\title{
Biorecovery of cobalt and nickel using biomass-free culture supernatants from Aspergillus niger
}

\author{
Yuyi Yang ${ }^{1} \cdot$ Wenjuan Song ${ }^{2} \cdot$ John Ferrier $^{1} \cdot$ Feixue Liu $^{1} \cdot$ Laszlo Csetenyi $^{3} \cdot$ Geoffrey Michael Gadd $^{1}$ (D)
}

Received: 6 August 2019 / Revised: 25 October 2019 / Accepted: 4 November 2019 / Published online: 28 November 2019

(C) The Author(s) 2019

\begin{abstract}
In this research, the capabilities of culture supernatants generated by the oxalate-producing fungus Aspergillus niger for the bioprecipitation and biorecovery of cobalt and nickel were investigated, as was the influence of extracellular polymeric substances (EPS) on these processes. The removal of cobalt from solution was $>90 \%$ for all tested Co concentrations: maximal nickel recovery was $>80 \%$. Energy-dispersive X-ray analysis (EDXA) and X-ray diffraction (XRD) confirmed the formation of cobalt and nickel oxalate. In a mixture of cobalt and nickel, cobalt oxalate appeared to predominate precipitation and was dependent on the mixture ratios of the two metals. The presence of EPS together with oxalate in solution decreased the recovery of nickel but did not influence the recovery of cobalt. Concentrations of extracellular protein showed a significant decrease after precipitation while no significant difference was found for extracellular polysaccharide concentrations before and after oxalate precipitation. These results showed that extracellular protein rather than extracellular polysaccharide played a more important role in influencing the biorecovery of metal oxalates from solution. Excitation-emission matrix (EEM) fluorescence spectroscopy showed that aromatic protein-like and hydrophobic acid-like substances from the EPS complexed with cobalt but did not for nickel. The humic acid-like substances from the EPS showed a higher affinity for cobalt than for nickel.
\end{abstract}

Keywords Aspergillus niger $\cdot$ Biorecovery $\cdot$ Extracellular polymeric substances $\cdot$ Fluorescence quenching $\cdot$ Cobalt $\cdot$ Nickel $\cdot$ Oxalate

\section{Introduction}

Microorganisms can play an important role in both the remediation and biorecovery of metals (Gadd 2010; Liang and Gadd 2017). Although metals cannot be degraded into harmless compounds, their chemical form, mobility, toxicity, and bioavailability can be changed via the growth, metabolism, and metabolic products of microorganisms (Peng et al. 2018). Metal immobilization or recovery from solution can

Geoffrey Michael Gadd

g.m.gadd@dundee.ac.uk

1 Geomicrobiology Group, School of Life Sciences, University of Dundee, Scotland DD1 5EH, UK

2 Xinjiang Institute of Ecology and Geography, Chinese Academy of Sciences, Urumqi 830011, China

3 Concrete Technology Group, Department of Civil Engineering, University of Dundee, Scotland DD1 5EH, UK be achieved by bioprecipitation where metals are transformed from soluble species to insoluble compounds, such as oxides, carbonates, phosphates, oxalates, and sulfides (Haferburg and Kothe 2007; Tsezos 2009; Gadd et al. 2014; Liang and Gadd 2017). For example, Fe, $\mathrm{Zn}$, and $\mathrm{Cd}$ in wastewater showed more than $99 \%$ precipitation rates in downflow fluidized bed reactors containing sulfate-reducing bacteria (SRB) (Gallegos-Garcia et al. 2009). Biological sulfide precipitation combined with solvent extraction can even result in nanosized metal sulfides for biorecovery (Nanusha et al. 2019). Microbially induced calcite precipitation (MICP) is also a promising biotechnology for recovery or immobilization of metals from wastewater or groundwater ( $\mathrm{Li}$ et al. 2014; $\mathrm{Li}$ and Gadd 2017a, b; Kumari et al. 2016; Zhu and Dittrich 2016; Torres-Aravena et al. 2018). A total of $61 \%$ of calcium and $56 \%$ of strontium precipitation rates were obtained in porous media reactors via MICP mediated by the bacterium Sporosarcina pasteurii (Lauchnor et al. 2013). Calcium recovery of more than $90 \%$ was achieved from a calcium-rich industrial wastewater using bacterial MICP (Hammes et al. 
2003). Supernatants obtained from ureolytic fungi are also very efficient in forming copper and other metal carbonate nanoparticles for biorecovery ( $\mathrm{Li}$ et al. 2014, 2015, 2019; Li and Gadd, 2017a, b; Liu et al. 2019).

Organic acids, e.g. oxalic acid produced by fungi, can also play an important role in the immobilization or biorecovery of metals (Clarholm et al. 2015; Gadd 1999; Gadd et al. 2014; Mishra et al. 2017; Yang et al. 2019). Wood-rotting fungi can immobilize toxic metals in a metal-amended substrate by precipitation as metal oxalates (Kaewdoung et al. 2016). Lead immobilization via oxalates was also found with fluorapatite and Aspergillus niger ( $\mathrm{Li}$ et al. 2016). In previous studies, it was also found that metabolites of the geoactive fungi Aspergillus niger and Beauveria caledonica could immobilize rare earth elements and toxic metals as oxalates (Fomina et al. 2005; Kang et al. 2019). Chemical oxalate precipitation is also widely used for the recovery of actinides (Abraham et al. 2014). High purity magnesium oxalate was obtained from Uyuni salar brine via chemical oxalate precipitation (Tran et al. 2013). Nickel is a primary co-existing element in Co minerals (Hazen et al. 2017), while industrially, cobalt, and nickel are also normal elements used in several kinds of batteries (Lupi et al. 2005; Rodrigues and Mansur 2010; Chen et al. 2011). In this research, we have used fungal products for biorecovery of cobalt and nickel from solution to (1) investigate the efficiency of culture supernatants from Aspergillus niger for cobalt and nickel biorecovery, (2) identify the bioprecipitation products formed, (3) determine the possible influence of extracellular polymeric substances (EPS) on the biorecovery process. This study will provide insights into the roles of fungal metabolites in metal-mineral interactions and their potential for metal biorecovery from solution.

\section{Methods and materials}

\section{Microorganism and media}

The experimental fungus used in this study was Aspergillus niger (ATCC 1015), which was incubated on malt extract agar slants (Lab M Limited, Heywood, Lancashire, UK) at $25^{\circ} \mathrm{C}$ in the dark for 7 days to prepare spore suspensions for inoculation of liquid media according to a previous study (Kang et al. 2019). Modified Czapek-Dox (MCD) medium consisted of (g L ${ }^{-1}$ Milli-Q water): D-glucose, $30 ; \mathrm{NaNO}_{3}, 3 ; \mathrm{Na}_{2} \mathrm{HPO}_{4}$, $1 ; \mathrm{MgSO}_{4} \cdot 7 \mathrm{H}_{2} \mathrm{O}, 0.5 ; \mathrm{KCl}, 0.5$; and $\mathrm{FeSO}_{4} \cdot 7 \mathrm{H}_{2} \mathrm{O}, 0.01$. All components were individually prepared as $100 \mathrm{~mL}$ stock solutions at the appropriate concentration and sterilized at 115 ${ }^{\circ} \mathrm{C}$ for 20 min prior to experiments. The initial $\mathrm{pH}$ of $\mathrm{MCD}$ media was adjusted to $\mathrm{pH} 5.5$ using $1 \mathrm{M} \mathrm{HCl}$ before autoclaving. The initial spore concentration in the medium was $5 \times$ $10^{5} \mathrm{~mL}^{-1}$. A. niger was grown in $100-\mathrm{mL}$ liquid medium in $250-\mathrm{mL}$ Erlenmeyer flasks incubated on a shaker at $150 \mathrm{rpm}$ at $25^{\circ} \mathrm{C}$ in the dark. Biomass-free culture supernatants after 1or 2-week incubation were obtained by filtering the medium through $0.45-\mu \mathrm{m}$ cellulose nitrate membrane filters (Minisart syringe filters, Sartorius, Göttingen, Germany). All chemicals were obtained from Sigma-Aldrich Ltd., St. Louis, MO, USA unless stated otherwise.

\section{Recovery of cobalt and nickel via bioprecipitation by fungal supernatants}

Different concentrations of cobalt, nickel, and their mixture were used to examine their recovery from solution as biogenic minerals. Aliquots from stock solutions of $100 \mathrm{mM}$ $\mathrm{CoCl}_{2} \cdot 4 \mathrm{H}_{2} \mathrm{O}$ and/or $\mathrm{NiCl}_{2} \cdot 6 \mathrm{H}_{2} \mathrm{O}$ were added to $27 \mathrm{~mL}$ biomass-free supernatants to reach a total volume of $30 \mathrm{~mL}$, with or without the addition of Milli-Q $\mathrm{H}_{2} \mathrm{O}$, in $50-\mathrm{mL}$ tubes and mixed at $60 \mathrm{rpm}$ for $24 \mathrm{~h}$ on a tube rotator. The resulting precipitate and supernatants from the tubes were collected after centrifugation (2012 g, $30 \mathrm{~min}$ ). The concentrations of cobalt and nickel in the supernatants were measured by atomic absorption spectrophotometry (AAS) (AAnalyst 400 Atomic Absorption Spectrophotometer, PerkinElmer Ltd., Beaconsfield, UK). All experiments were carried out at least in triplicate.

Environmental scanning electron microscopy (ESEM) and X-ray diffraction (XRD) analysis of the collected precipitates were used to examine the morphology and mineralogical composition of the precipitated minerals. Detailed experimental procedures can be found in previous publications ( $\mathrm{Li}$ et al. 2014; Li and Gadd 2017a). Precipitates were dried in a desiccator at ambient temperature for at least 5 days, mounted on aluminum stubs using carbon adhesive tape and coated with $10 \mathrm{~nm} \mathrm{Au} / \mathrm{Pd}$ using a Cressington 208HR sputter coater (Cressington, Watford, UK) and examined using a Philips XL30 ESEM (Philips XL 30 ESEM FEG) operating at an accelerating voltage of $15 \mathrm{kV}$. The mineral phases of the precipitates were identified using a Hiltonbrooks X-ray diffractometer (HiltonBrooks Ltd., Crewe, UK) equipped with a single graphite crystal monochromatic $\mathrm{CuK} \alpha$ chronometer (30 mA, $40 \mathrm{kV})$.

\section{Influence of extracellular polymeric substances on recovery of cobalt and nickel}

Supernatants were collected from MCD media after growth of A. niger and then dialyzed using dialysis membrane to obtain an extracellular polymeric substances (EPS) solution. Twentyfive millimolar of sodium oxalate was dissolved in the EPS solution, and the $\mathrm{pH}$ was adjusted to $\mathrm{pH} 2.2$ using $1 \mathrm{M} \mathrm{HCl}$, the same value as in oxalate-free supernatants. The EPS solution containing oxalate was then used to precipitate cobalt and nickel from single and mixed solutions and using a $25-\mathrm{mM}$ sodium oxalate solution treatment as a control. The content of 
extracellular polysaccharide and protein before and after precipitation was determined using the phenol-sulfuric acid method (DuBois et al. 1956) and Bradford method (Bradford 1976), respectively.

\section{Excitation emission matrix fluorescence spectroscopy and quenching titrations}

A Hitachi F-7000 fluorescence spectroscope (Hitachi, Tokyo, Japan), equipped with a $1.0-\mathrm{cm}$ quartz cell and thermostatic bath, was used to determine the excitation emission matrix (EEM) spectra of EPS obtained from the A. niger culture supernatants. EEM spectra were obtained according to published methods (Song et al. 2012; Wang et al. 2018). For the quenching titration, the EPS solution was titrated with incremental microliter additions of $\mathrm{Co}$ (II) and $\mathrm{Ni}(\mathrm{II})$ solution at $308 \mathrm{~K}\left(35^{\circ} \mathrm{C}\right)$. After each addition of metal salt, the solution was mixed using a magnetic stirrer for $15 \mathrm{~min}$ and EEM spectra were recorded during this process. Fifteen minutes was set as the equilibrium time because the fluorescence intensities showed almost no change after 15 -min reaction.

\section{Results}

\section{Recovery of cobalt and nickel as oxalate minerals using $A$. niger biomass-free culture supernatants}

The biomass-free supernatants collected from A. niger liquid cultures after 7 and 14 days exhibited excellent precipitation and recovery of cobalt from solution (Fig. 1). Recovery of cobalt from solution was above $90 \%$ for all tested cobalt concentrations. There was no significant

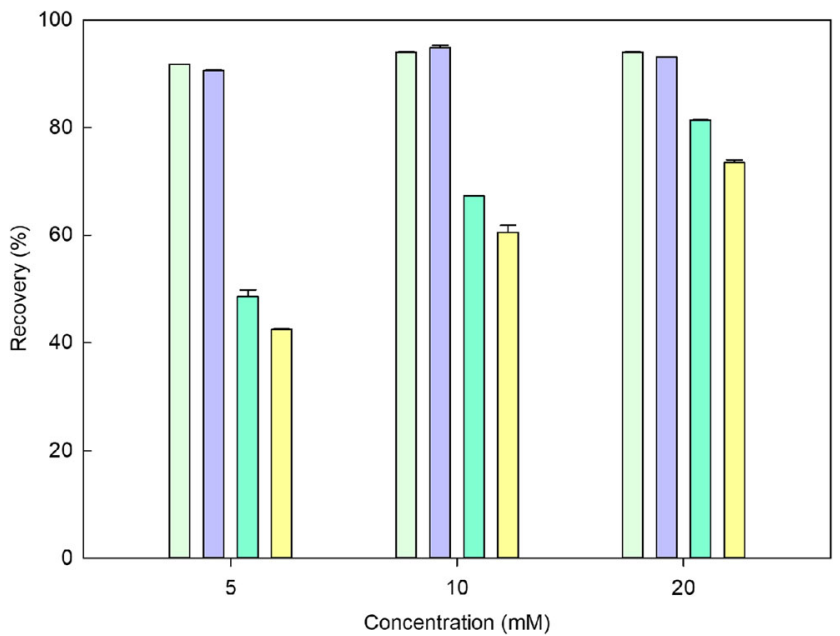

Fig. 1 Removal of cobalt and nickel from solution using supernatants of A. niger ( $\square$ 7-day supernatants $+\mathrm{Co} ; \square$ 14-day supernatants + $\mathrm{Co} ; \square$ 7-day supernatants $+\mathrm{Ni}$ $\square$ 14-day supernatants $+\mathrm{Ni})$. Bars are the standard error of the mean $(n=3)$ difference in cobalt recovery between supernatants harvested after 7 and 14 days $(p>0.05)$. Nickel precipitation and recovery from $A$. niger 7 - and 14-day-old supernatants increased as the concentration of nickel increased from 5 to $20 \mathrm{mM}$. Maximum recovery $(81.44 \%)$ of nickel occurred at a concentration of $20 \mathrm{mM} \mathrm{NiCl} \cdot 6 \mathrm{H}_{2} \mathrm{O}$ using supernatants collected after 7 days. The 7-day-old supernatants collected from A. niger cultures exhibited significantly higher recovery of nickel than supernatants collected after 14 days $(p<0.05)$. Since the 7-day old supernatants exhibited such high recovery rates for both cobalt and nickel, these were used for subsequent experiments. Figure 2 shows the recovery of cobalt and nickel from solutions with different concentration ratios (1:1,1:2 and 1:4). The results revealed that the removal of cobalt from a mixture of cobalt and nickel were all above $98 \%$, except for $2.5 \mathrm{mM}$ cobalt and nickel. The recovery of nickel from the mixture was in the range $44.9-93.1 \%$. Recovery of cobalt and nickel from the supernatants therefore depended on the mixture ratios of the two metals.

\section{Influence of extracellular polymeric substances on recovery of cobalt and nickel}

The influence of EPS on the efficiency of metal removal was investigated. From Fig. 3, it can be seen that EPS did not influence the recovery of cobalt from solution. However, the presence of EPS decreased nickel recovery significantly. Nickel recoveries from $10 \mathrm{mM}$ nickel and a mixed solution of $5 \mathrm{mM}$ cobalt and $5 \mathrm{mM}$ nickel using a chemical oxalate solution were $59.1 \%$ and $98.2 \%$, respectively. When using an EPS solution containing oxalate, nickel recoveries from $10 \mathrm{mM}$ nickel and a mixed solution of $5 \mathrm{mM}$ cobalt and $5 \mathrm{mM}$ nickel were $38.5 \%$ and

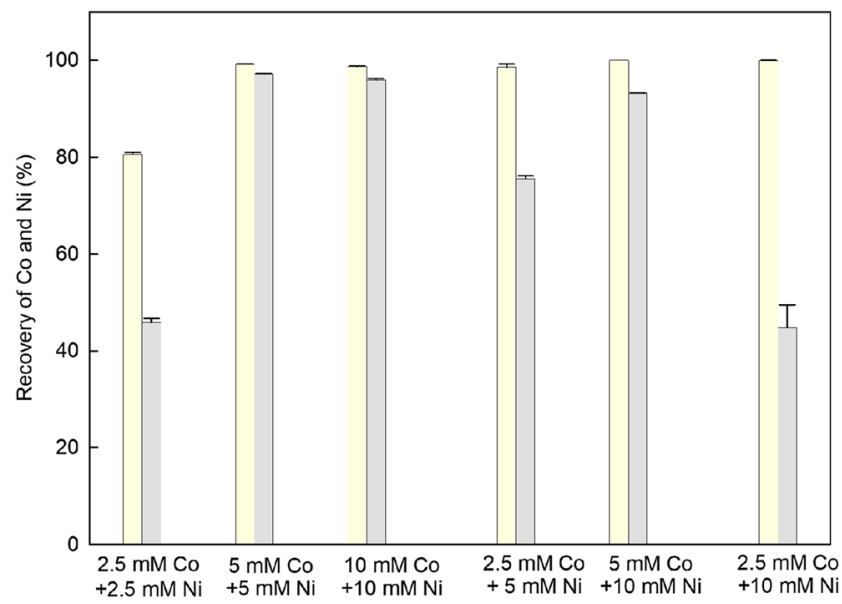

Fig. 2 The removal of cobalt and nickel from a mixed solution using supernatants of $A$. niger collected after 7 days ( $\square$ Co; $\mathrm{Ni})$. Bars are the standard error of the mean $(n=3)$ 


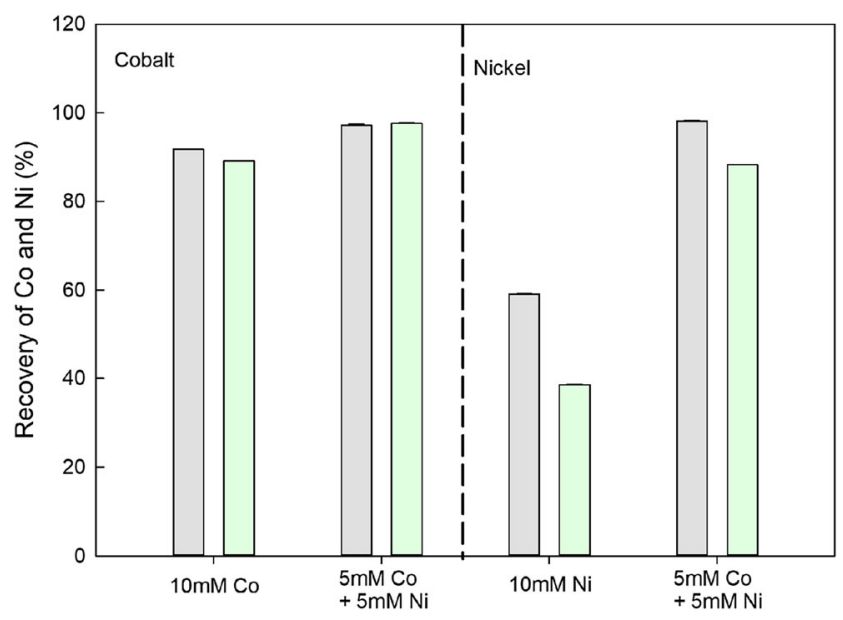

Fig. 3 The removal of cobalt and nickel from solutions using oxalate with or without extracellular polymeric substances (EPS) ( $\square$ oxalate; oxalate + EPS). Bars are the standard error of the mean $(n=3)$

$88.3 \%$, respectively. The polysaccharide concentration in the EPS solution before precipitation was $1.50 \mathrm{mg} \mathrm{L}^{-1}$ (Fig. 4). Extracellular polysaccharide concentrations in solution after precipitation of cobalt and nickel from single solutions and their mixture were $1.40,1.39$, and $1.40 \mathrm{mg} \mathrm{L}^{-1}$, respectively. An insignificant decrease in the extracellular polysaccharide concentration therefore occurred after oxalate precipitation. The concentration of extracellular protein before precipitation was $1.88 \mathrm{mg} \mathrm{L}^{-1}$. Extracellular protein concentrations in solution after precipitation with cobalt, nickel, and their mixture were 0.83 , 1.25 , and $0.61 \mathrm{mg} \mathrm{L}^{-1}$, respectively. A significant reduction of extracellular protein in solution therefore resulted after oxalate precipitation $(p<0.05)$. It can also be noted that more extracellular protein disappeared during the cobalt treatment compared to the nickel treatment.

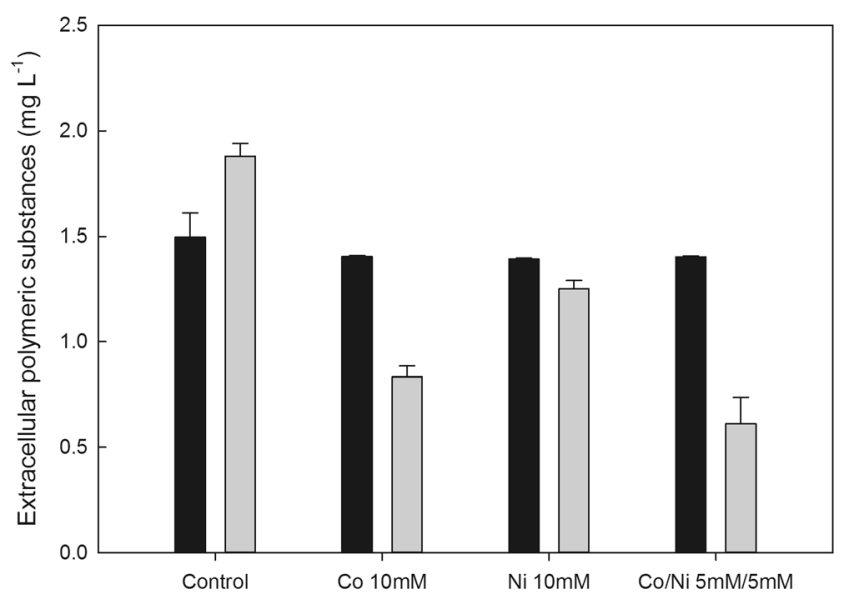

Fig. 4 Changes in extracellular polymeric substances (EPS) concentration before and after removal of cobalt and nickel using oxalate with EPS ( extracellular polysaccharide; extracellular protein). Bars are the standard error of the mean $(n=3)$

\section{Characterization of cobalt and nickel oxalate minerals}

Figure 5 shows the morphology of cobalt and nickel crystal precipitates obtained under different experimental conditions. Micro-rod shaped crystals were obtained for cobalt with biomass-free supernatants, EPS solution containing oxalate, and chemically prepared oxalate solution. Micropolyhedrons were observed for nickel when reacted with culture supernatants, EPS solution containing oxalate, and chemically prepared oxalate solution. No obvious differences were apparent between the three treatments for cobalt and nickel precipitation from single metal solutions suggesting that neither supernatants nor the EPS solution had an influence on precipitate morphology in the single metal solutions. However, crystalline morphology observed in the metal mixture was as a smooth layered form using supernatants and EPS solution containing oxalate in contrast to the precipitate from a mixture of nickel and cobalt using chemically prepared oxalate which displayed a rough and non-uniform shape. This demonstrated that the supernatants containing EPS influenced the morphology of precipitated minerals in a mixture of cobalt and nickel compared with chemical oxalate. Figure 6 shows EDXA and XRD of the precipitation obtained using supernatants with single solutions of cobalt, nickel, and their mixture. The elemental composition of $\mathrm{C}, \mathrm{O}$, and $\mathrm{Co} / \mathrm{Ni}$ from EDXA and the XRD pattern of the mineral precipitate using supernatants with single cobalt or nickel solution showed that cobalt or nickel oxalate formed (Fig. 6a, b). For the precipitate produced from the mixture of cobalt and nickel, EDXA showed that it was composed of cobalt, nickel, carbon and oxygen. However, the XRD pattern of a mixed $\mathrm{Co} /$ Ni solution showed more similarity with cobalt oxalate (Fig. 6c). This could suggest a difficulty in distinguishing $\mathrm{Co}$ and $\mathrm{Ni}$ oxalate when precipitating together. In addition, it is possible that a mixed Co-Ni oxalate phase may exist as well as adsorption or other kinds of association with the crystals in poorly or non-crystallized forms.

\section{Fluorescence properties of EPS from A. niger}

Three-dimensional fluorescence spectra of EPS from Aspergillus niger in the absence and presence of the metals are shown in Fig. 7. Four fluorescence peaks were obtained in the EEM spectra of EPS. Peaks A (Ex/Em 230/325-340) and B (Ex/Em 235/400-405) can be attributed to aromatic proteinlike and hydrophobic acid-like fluorophores, respectively; peak C (Ex/Em 275-280/340) and D (Ex/Em 290-295/405) is attributed to humic acid-like fluorophores (Chen et al., 2003). The fluorescence position and intensity of EPS in the absence and presence of different metal ions at the concentration of $3.67 \mathrm{mM}$ are shown in Table 1. For most fluorescence peaks, the fluorescence intensity decreased after the addition of cobalt and nickel indicating that cobalt and nickel could quench the fluorescence of most fluorescent substances, 
Fig. 5 Scanning electron microscopy images of the $\mathrm{Co} / \mathrm{Ni}$ precipitates $(10 \mathrm{mM}$ cobalt, $10 \mathrm{mM}$ nickel and a mixture of $5 \mathrm{mM}$ cobalt and $5 \mathrm{mM}$ nickel reacted with culture supernatants, oxalate with EPS and oxalate, respectively). Scale bars $(1 \mu \mathrm{m})$. Typical images are shown from several separate examinations

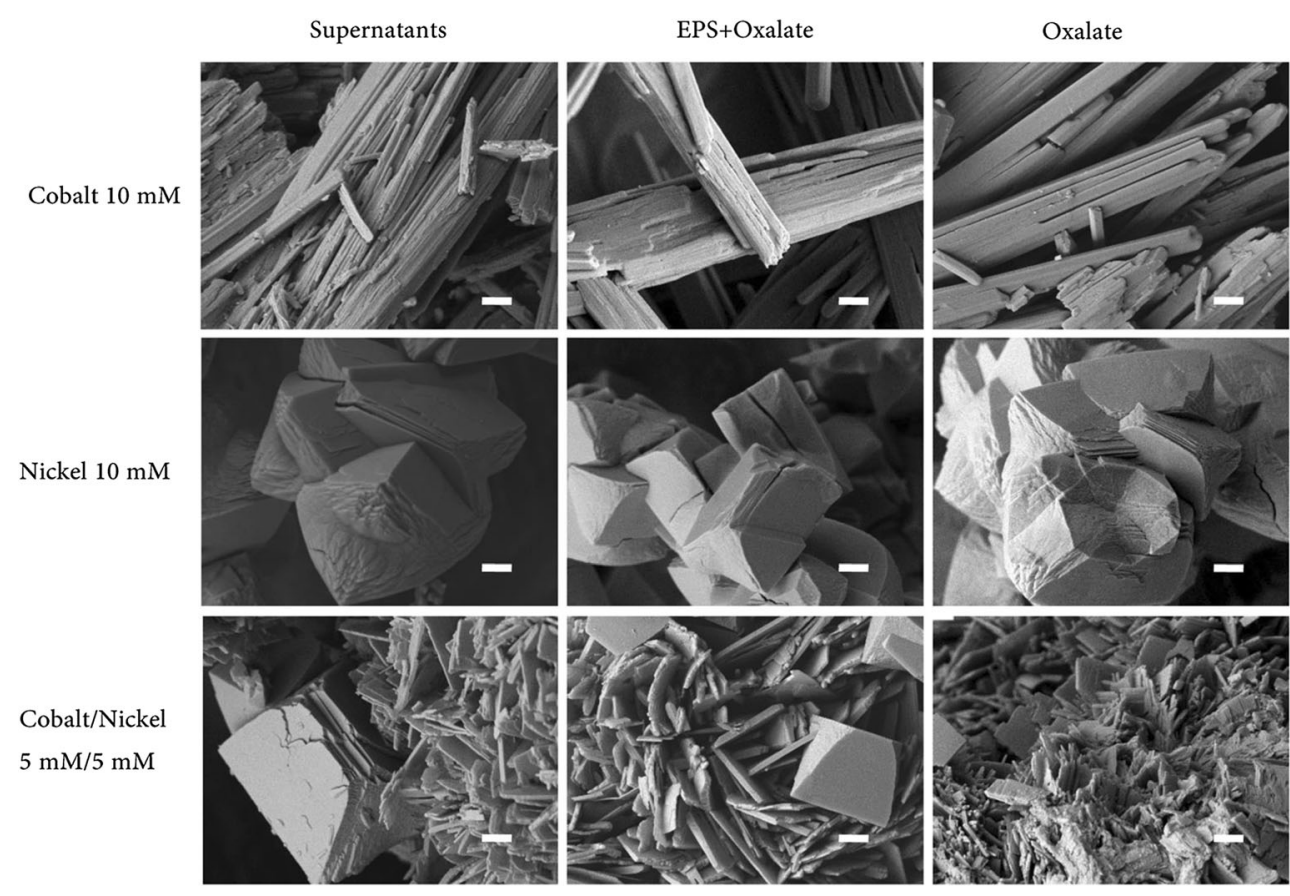

especially aromatic protein-like (peak A) and humic acid-like (peak C) substances. The fluorescence intensity of hydrophobic acid-like substances (peak B) showed little change after addition of nickel, showing that nickel did not quench its fluorescence but cobalt did. Otherwise, nickel could quench the fluorescence of the other kind of humic acid-like substances (peak D) and the increasing intensity after addition of cobalt indicated that more fluorophores might be unfolded under cobalt stress.

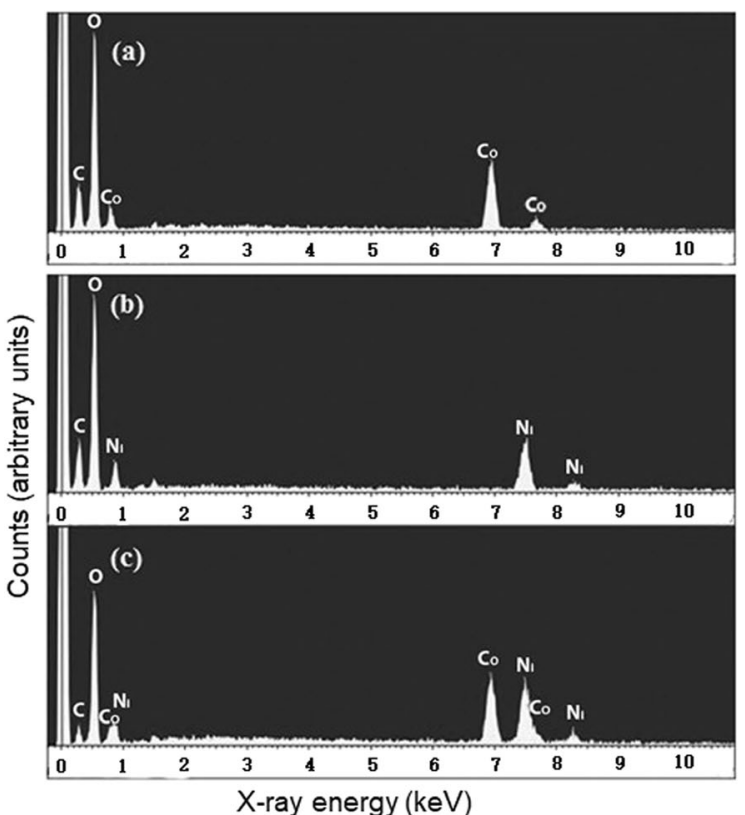

\section{Fluorescence quenching}

The fluorescence quenching process can be dynamic quenching, which is due to collision between the fluorophore and quencher, or static quenching due to complexation between the fluorophore and the quencher. The Stern-Volmer Eq. (1) was used to judge whether the quenching processes were dynamic or static (Keizer 1983):

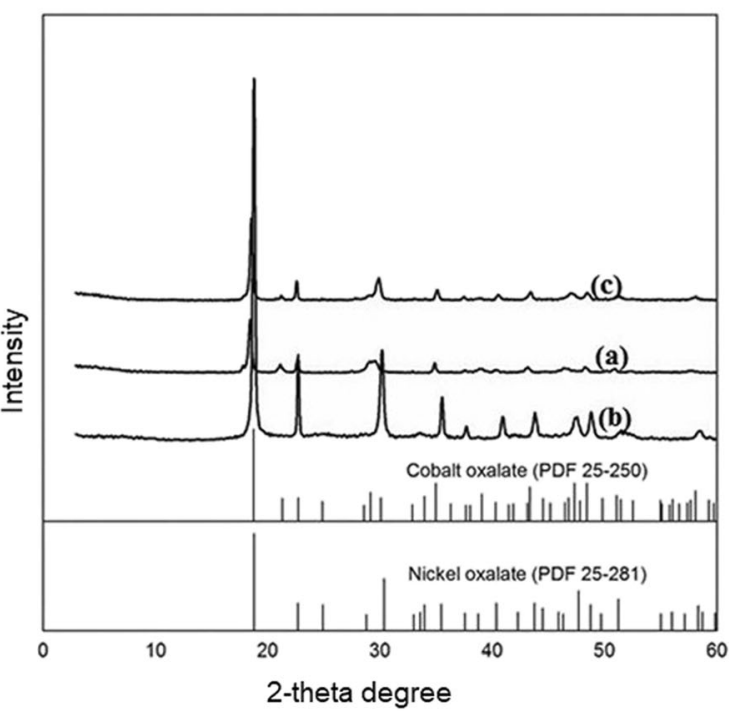

Fig. 6 Energy-dispersive X-ray analysis (EDXA) and X-ray diffraction (XRD) of the bioprecipitates using obtained culture supernatants reacted with $10 \mathrm{mM}$ cobalt (a), $10 \mathrm{mM}$ nickel (b), and mixture of $5 \mathrm{mM}$ cobalt and $5 \mathrm{mM}$ nickel (c). Typical images are shown from several separate examinations 

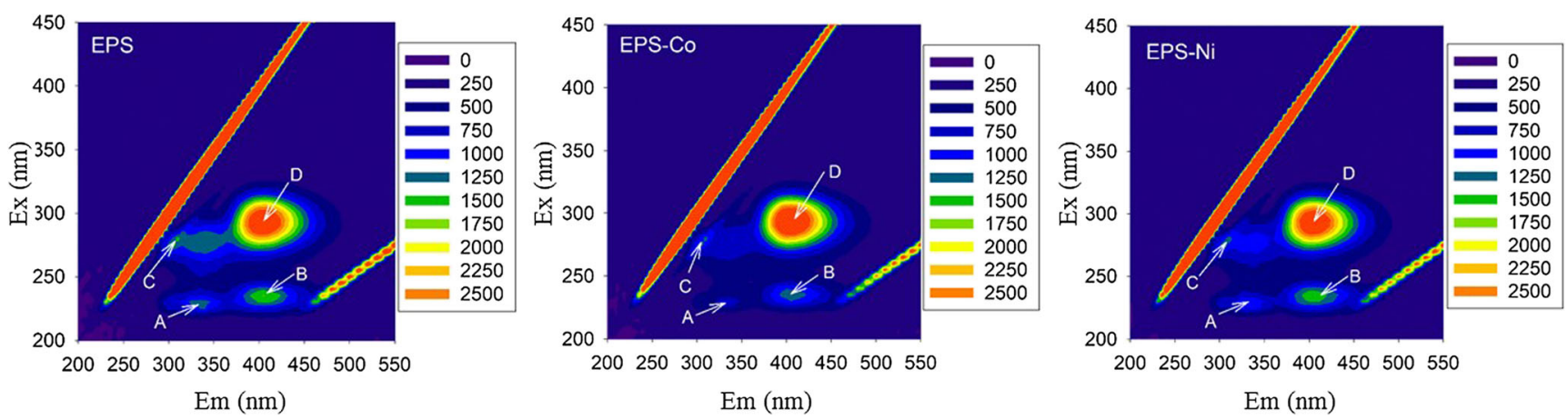

Fig. 7 EEM spectra of EPS at $25^{\circ} \mathrm{C}$ in the absence and presence of metal ions ( $5 \mathrm{mM}$ cobalt and nickel). Typical spectra are shown from several separate determinations

$$
F_{0} / F=1+k_{q} \tau_{0}[Q]=1+K_{s v}[Q]
$$

where $F_{0}$ and $F$ represent the fluorescence intensity in the absence and presence of the quencher, respectively; $K_{\mathrm{q}}$ is the quenching rate constant; $K_{\mathrm{sv}}$ is the quenching constant; $\tau_{0}$ is the average lifetime of the fluorescence in the absence of quencher, which is taken as $10^{-8} \mathrm{~s}$; and $[Q]$ is the metal concentration. The values of the quenching constants $\left(K_{\mathrm{sv}}\right)$ and $R^{2}$ are summarized in Table 2.

The quenching rate constant $\left(K_{\mathrm{q}}\right)$ values were one order of magnitude larger than the maximum diffusion collision quenching rate constant $\left(2.0 \times 10^{10} / \mathrm{M} / \mathrm{s}\right)$, indicating that the fluorescence quenching process was mainly governed by static quenching by formation of complexes. However, if the $K_{\mathrm{q}}$ value was smaller than $2.0 \times 10^{10} / \mathrm{M} / \mathrm{s}$, this indicated the fluorescence quenching process was dominated by dynamic quenching by intermolecular collisions. According to the quenching constant rates shown in Table 2, it was observed that the fluorescence quenching of EPS by cobalt was due to complexation. The fluorescence quenching of EPS by Ni was both a dynamic (peak A and peak D) and static process (peak C). Furthermore, the quenching strength of cobalt to fluorescence of EPS was larger than that for nickel.

\section{Binding constants and binding sites}

For ligand molecules that bind independently to a set of equivalent sites on a macromolecule, the equilibrium between free and bound molecules is given by the Hill (2013) Eq. (2): $\log \left[\left(F_{0}-F\right) / F\right]=\log K_{b}+n \log [Q]$

where $F_{0}$ and $F$ are the fluorescence intensities in the absence and presence of quencher, respectively; $K_{\mathrm{b}}$ is the binding constant; $n$ is the number of binding sites; and $[Q]$ is the concentration of metal. The binding constant $\left(K_{\mathrm{b}}\right)$ reflects the interactive intensity between EPS and the metal.

The binding constants $\left(\log K_{\mathrm{b}}\right)$ and the number of binding sites $(n)$ of the EPS-metal system are listed in Table 3. The aromatic protein-like (peak A) and hydrophobic acid-like substances (peak B) possessed cobalt binding ability but exhibited no complexation with nickel. Both the binding ability and binding sites of cobalt with humic acid-like substances (peak C) were much larger than those for nickel. The maximum value of $\log K_{\mathrm{b}}$ was obtained from the EPS-cobalt system at peak $\mathrm{B}$, indicating that hydrophobic acid-like fluorophores possessed a strong binding ability for cobalt.

\section{Discussion}

Bioprecipitation is regarded as a potential technique for the removal and recovery of metals from solution (Gadd et al. 2014; Gadd and Pan 2016; Liang and Gadd 2017; TorresAravena et al. 2018). For example, carbonates, oxides, phosphates, and oxalates produced by microbial activities can transform metals from soluble species into the corresponding insoluble compounds via precipitation (Li and Gadd 2017a, b; Liang and Gadd 2017; Peng et al. 2018). Oxalic acid is produced by a wide variety of fungi, and this plays an important
Table 1 The fluorescence position $(\mathrm{Ex} / \mathrm{Em}, \mathrm{nm})$ and intensity (arbitrary units) of EPS in the absence and presence of cobalt and nickel at concentrations of $3.67 \mathrm{mM}$

\begin{tabular}{|c|c|c|c|c|c|c|c|c|}
\hline \multirow[t]{2}{*}{ System } & \multicolumn{2}{|l|}{ Peak A } & \multicolumn{2}{|l|}{ Peak B } & \multicolumn{2}{|l|}{ Peak C } & \multicolumn{2}{|l|}{ Peak D } \\
\hline & $\mathrm{Ex} / \mathrm{Em}$ & Intensity & $\mathrm{Ex} / \mathrm{Em}$ & Intensity & $\mathrm{Ex} / \mathrm{Em}$ & Intensity & $\mathrm{Ex} / \mathrm{Em}$ & Intensity \\
\hline EPS & $230 / 335$ & 1070 & $235 / 405$ & 1473 & $275 / 340$ & 1216 & $295 / 405$ & 3198 \\
\hline EPS-Co & $230 / 335$ & 748 & $235 / 405$ & 1300 & $275 / 340$ & 891 & $295 / 405$ & 3353 \\
\hline EPS-Ni & $230 / 340$ & 953 & $235 / 400$ & 1435 & $275 / 340$ & 888 & $295 / 405$ & 3062 \\
\hline
\end{tabular}


Table 2 Stern-Volmer fluorescence quenching constant, $K_{\mathrm{sv}}$, and quenching rate constant, $K_{\mathrm{q}}$, of EPS in the presence of different metals (cobalt concentration range $0-5.67 \mathrm{mM}$; nickel concentration range 0 $3.67 \mathrm{mM} ; R^{2}$ : determination coefficients)

\begin{tabular}{lllll}
\hline \multicolumn{2}{l}{ Quencher } & $\begin{array}{l}\text { Quenching constants, } \\
K_{\text {sv }}\left(\times 10^{3} / \mathrm{M}\right)\end{array}$ & $\begin{array}{l}\text { Quenching rate } \\
\text { constants, } \\
K_{\mathrm{q}}\left(\times 10^{11} / \mathrm{M} / \mathrm{s}\right)\end{array}$ & \\
\hline & & 4.906 & 0.9703 \\
\hline Co & Peak A & 4.906 & 1.801 & 0.9188 \\
& Peak B & 1.801 & 3.850 & 0.9772 \\
& Peak C & 3.850 & - & - \\
& Peak D & - & 0.786 & 0.2010 \\
Ni & Peak A & 0.786 & - & - \\
& Peak B & - & 2.927 & 0.8817 \\
& Peak C & 2.927 & 0.592 & 0.2531 \\
\hline
\end{tabular}

role in metal detoxification, weathering and cycling of metals, bioleaching, and biomineralization (Anjum et al. 2010; Fomina et al. 2008; Gadd 2007; Gadd et al. 2014; Kang et al. 2019; Nancharaiah et al. 2016; Yang et al. 2019). Metal oxalate crystal formation has been widely found using Aspergillus species, such as zinc oxalate (Sutjaritvorakul et al. 2016), lanthanum oxalate (Kang et al. 2019), manganese oxalate (Wei et al. 2012), and calcium oxalate (Pinzari et al. 2010). Chemically produced oxalate has also been used as a precipitant for recovery of valuable metals from a bioleaching solution of spent lithium-ion batteries (Sun and Qiu 2012) and as a leaching solution for monazite (de Vasconcellos et al. 2006). Copper recovery can reach $99.5 \%$ using chemical oxalate precipitation (Gyliene and Salkauskas 1995). Cobalt recovery from a spent lithium-ion batteries leachate could reach $\sim 93 \%$ using chemical oxalate (Chen et al. 2011). In this work, approximately $94 \%$ and $98 \%$ cobalt recovery from a $10-\mathrm{mM}$ solution were obtained using biomass-free $A$. niger culture supernatants and chemical oxalate, respectively, thus demonstrating that supernatants from $A$. niger were almost as efficient as chemical means to recover cobalt via bioprecipitation. Moreover, culture supernatants were more efficient for recovery of nickel compared with the chemical oxalate treatment. In a $\mathrm{Co} / \mathrm{Ni}$ mixture, cobalt and nickel recoveries were increased

Table 3 Binding constants $\left(\log K_{\mathrm{b}}\right)$ and binding sites $(n)$ of peaks A, B, and $\mathrm{C}$ from EPS complexation with different metals (cobalt concentration range $0-5.67 \mathrm{mM}$; nickel concentration range $0-3.67 \mathrm{mM} ; R^{2}$ : determination coefficients)

\begin{tabular}{lllll}
\hline \multicolumn{2}{l}{ Metal ion } & $\begin{array}{l}\text { Binding constant, } \\
\log K_{\mathrm{b}}\end{array}$ & Binding sites $n$ & $R^{2}$ \\
\hline Co & Peak A & 3.56 & 1.62 & 0.9564 \\
& Peak B & 6.65 & 3.16 & 0.9664 \\
& Peak C & 3.20 & 1.51 & 0.9575 \\
Ni & Peak C & 1.51 & 0.85 & 0.8517 \\
\hline
\end{tabular}

compared to the single metal treatments. However, the apparent dominance of cobalt oxalate in the mixed $\mathrm{Co} / \mathrm{Ni}$ precipitate could be explained by the solubility product constants $(K s p)$ of the two oxalate minerals. The Ksp of cobalt oxalate $\left(2.70 \times 10^{-9}\right)$ is significantly smaller than that of nickel oxalate $\left(1.2 \times 10^{-3}\right)$ (IUPAC-NIST Solubility Database).

Extracellular polymeric substances (proteins and/or polysaccharides) can play an important role in biomineralization, regulating and controlling nucleation, and growth of crystal structures (Ercole et al. 2012; Kawaguchi and Decho 2002; Li and Gadd 2017a, b; Perri et al. 2018; Tourney and Ngwenya 2014). In our study, it was found that the supernatants, or EPS obtained from supernatants, did not exert a significant influence on crystal morphology compared with chemical methods during the formation of cobalt and nickel oxalate. Only for the $\mathrm{Co} / \mathrm{Ni}-$ mixed solution was there a difference in crystal morphology between those derived from the supernatants and the chemical system (Fig. 5). In other studies, fungal growth supernatants from Neurospora crassa were found to greatly influence the scale of crystal morphology for metal carbonates (Li and Gadd 2017a, b). Although EPS did not change the morphology of the nickel precipitate in the single metal solution, it did influence nickel recovery (Fig. 3).

In other studies, significant amounts of extracellular protein in fungal supernatants were removed by precipitation of copper carbonate (Li and Gadd 2017a, b; Liu et al. 2019). Here, extracellular protein was only partly removed during oxalate precipitation, while the extracellular polysaccharide concentration did not show much change compared to the control. Much more protein was removed with cobalt compared to nickel. It is well known that extracellular polymeric substances contain a variety of metal-binding groups (Wang et al. 2014; Liu et al. 2015; Song et al. 2016). Lower binding affinities between nickel and EPS could lead to a decrease in recovery of $\mathrm{Ni}$ in the presence of EPS in the oxalate solution compared to cobalt (Fig. 3). The aromatic protein-like, hydrophobic acid-like substances and humic acid-like substances (peak C) had a clear binding affinity for cobalt. Aromatic protein-like and humic acid-like substances have been found to easily trap copper (Wang et al. 2015; Wei et al. 2017). The differences in affinities of these substances for metals could explain the differences in the recovery efficiency for cobalt and nickel influenced by EPS. This work has demonstrated that fungal derived oxalate can be used for the recovery of cobalt from solution and provides insights into the role of other extracellular products during this process.

Acknowledgments We gratefully thank Yongchang Fan (School of Science and Engineering, University of Dundee, Dundee, DD1 4HN, Scotland, UK) for assistance with scanning electron microscopy.

Funding information GMG received research funding from the Natural Environment Research Council (NE/M011275/1 (COG ${ }^{3}$ - The geology, geometallurgy and geomicrobiology of cobalt resources leading to new 
product streams)). GMG also received additional research support of the Geomicrobiology Group from NERC (TeaSe project: NE/M010910/1). $\mathrm{JF}$ received receipt of a NERC $\mathrm{PhD}$ studentship as part of the $\mathrm{COG}^{3}$ award.

\section{Compliance with ethical standards}

Conflict of interest The authors declare that they have no competing interests.

Ethical statement This article does not contain any data from studies on human participants or animals performed by any of the authors.

Open Access This article is distributed under the terms of the Creative Commons Attribution 4.0 International License (http:// creativecommons.org/licenses/by/4.0/), which permits unrestricted use, distribution, and reproduction in any medium, provided you give appropriate credit to the original author(s) and the source, provide a link to the Creative Commons license, and indicate if changes were made.

\section{References}

Abraham F, Arab-Chapelet B, Rivenet M, Tamain C, Grandjean S (2014) Actinide oxalates, solid state structures and applications. Coord Chem Rev 266-267:28-68

Anjum F, Bhatti HN, Asgher M, Shahid M (2010) Leaching of metal ions from black shale by organic acids produced by Aspergillus niger. Appl Clay Sci 47:356-361

Bradford MM (1976) A rapid and sensitive method for the quantitation of microgram quantities of protein utilizing the principle of protein-dye binding. Anal Biochem 72:248-354

Chen W, Westerhoff P, Leenheer JA, Booksh K (2003) Fluorescence excitation-emission matrix regional integration to quantify spectra for dissolved organic matter. Environ Sci Technol 37:701-710

Chen L, Tang X, Zhang Y, Li L, Zeng Z, Zhang Y (2011) Process for the recovery of cobalt oxalate from spent lithium-ion batteries. Hydrometallurgy 108:80-86

Clarholm M, Skyllberg U, Rosling A (2015) Organic acid induced release of nutrients from metal-stabilized soil organic matter - the unbutton model. Soil Biol Biochem 84:168-176

de Vasconcellos ME, da Rocha SMR, Pedreira WR, da Queiroz SCA, Abrão A (2006) Enrichment of yttrium from rare earth concentrate by ammonium carbonate leaching and peroxide precipitation. $\mathrm{J}$ Alloys Compd 418:200-203

DuBois M, Gilles KA, Hamilton JK, Rebers PA, Smith F (1956) Colorimetric method for determination of sugars and related substances. Anal Chem 28:350-356

Ercole C, Bozzelli P, Altieri F, Cacchio P, Del Gallo M (2012) Calcium carbonate mineralization: involvement of extracellular polymeric materials isolated from calcifying bacteria. Microsc Microanal 18: 829-839

Fomina M, Hillier S, Charnock JM, Melville K, Alexander IJ, Gadd GM (2005) Role of oxalic acid overexcretion in transformations of toxic metal minerals by Beauveria caledonica. Appl Environ Microbiol $71: 371-381$

Fomina M, Charnock JM, Hillier S, Alvarez R, Livens F, Gadd GM (2008) Role of fungi in the biogeochemical fate of depleted uranium. Curr Biol 18:375-377

Gadd GM (1999) Fungal production of citric and oxalic acid: importance in metal speciation, physiology and biogeochemical processes. Adv Microb Physiol 41:47-92
Gadd GM (2007) Geomycology: biogeochemical transformations of rocks, minerals, metals and radionuclides by fungi, bioweathering and bioremediation. Mycol Res 111:3-49

Gadd GM (2010) Metals, minerals and microbes: geomicrobiology and bioremediation. Microbiology 156:609-643

Gadd GM, Pan X (2016) Biomineralization, bioremediation and biorecovery of toxic metals and radionuclides. Geomicrobiol J 33: $175-178$

Gadd GM, Bahri-Esfahani J, Li Q, Rhee YJ, Wei Z, Fomina M, Liang X (2014) Oxalate production by fungi: significance in geomycology, biodeterioration and bioremediation. Fungal Biol Rev 28:36-55

Gallegos-Garcia M, Celis LB, Rangel-Méndez R, Razo-Flores E (2009) Precipitation and recovery of metal sulfides from metal containing acidic wastewater in a sulfidogenic down-flow fluidized bed reactor. Biotechnol Bioeng 102:91-99

Gyliene O, Salkauskas M (1995) Metal recovery from spent electroless plating solutions by oxalate precipitation. Plat Surf Finish 82:61-63

Haferburg G, Kothe E (2007) Microbes and metals: interactions in the environment. J Basic Microbiol 47:453-467

Hammes F, Seka A, de Knijf S, Verstraete W (2003) A novel approach to calcium removal from calcium-rich industrial wastewater. Water Res 37:699-704

Hazen RM, Hystad G, Golden JJ, Hummer DR, Liu C, Downs RT, Morrison SM, Ralph J, Grew ES (2017) Cobalt mineral ecology. Am Mineral 102:108-116

Hill TL (2013) Cooperativity theory in biochemistry: steady-state and equilibrium systems. Springer-Verlag, New York

Kaewdoung B, Sutjaritvorakul T, Gadd GM, Whalley AJS, Sihanonth P (2016) Heavy metal tolerance and biotransformation of toxic metal compounds by new isolates of wood-rotting fungi from Thailand. Geomicrobiol J 33:283-288

Kang X, Csetenyi L, Gadd GM (2019) Biotransformation of lanthanum by Aspergillus niger. 103:981-993

Kawaguchi T, Decho AW (2002) A laboratory investigation of cyanobacterial extracellular polymeric secretions (EPS) in influencing $\mathrm{CaCO}_{3}$ polymorphism. J Cryst Growth 240:230-235

Keizer J (1983) Nonlinear fluorescence quenching and the origin of positive curvature in stern-Volmer plots. J Am Chem Soc 105:1494 1498

Kumari D, Qian X-Y, Pan X, Achal V, Li Q, Gadd GM (2016) Microbially-induced carbonate precipitation for immobilization of toxic metals. Adv Appl Microbiol 94:79-108

Lauchnor EG, Schultz LN, Bugni S, Mitchell AC, Cunningham AB, Gerlach R (2013) Bacterially induced calcium carbonate precipitation and strontium coprecipitation in a porous media flow system. Environ Sci Technol 47:1557-1564

Li Q, Gadd GM (2017a) Biosynthesis of copper carbonate nanoparticles by ureolytic fungi. Appl Microbiol Biotechnol 101:7397-7407

Li Q, Gadd GM (2017b) Fungal nanoscale metal carbonates and production of electrochemical materials. Microb Biotechnol 10:1131-1136

Li Q, Csetenyi L, Gadd GM (2014) Biomineralization of metal carbonates by Neurospora crassa. Environ Sci Technol 48:4409-4416

Li Q, Csetenyi L, Paton GI, Gadd GM (2015) $\mathrm{CaCO}_{3}$ and $\mathrm{SrCO}_{3}$ bioprecipitation by fungi isolated from calcareous soil. Environ Microbiol 17:3082-3097

Li, Q., Liu, D., Chen, C., Shao, Z., Wang, H., Liu, J., Zhang, Q. and Gadd, G.M. (2019). Experimental and geochemical simulation of nickel carbonate mineral precipitation by carbonate-laden ureolytic fungal culture supernatants. Environ Sci Nano 6:1866-1875

Li Z, Wang F, Bai T, Tao J, Guo J, Yang M, Wang S, Hu S (2016) Lead immobilization by geological fluorapatite and fungus Aspergillus niger. J Hazard Mater 320:386-392

Liang X, Gadd GM (2017) Metal and metalloid biorecovery using fungi. Microb Biotechnol 10:1199-1205

Liu W, Zhang J, Jin Y, Zhao X, Cai Z (2015) Adsorption of Pb(II), cd(II) and $\mathrm{Zn}(\mathrm{II})$ by extracellular polymeric substances extracted from 
Liang X, Gadd GM (2017) Metal and metalloid biorecovery using fungi. Microb Biotechnol 10:1199-1205

Liu W, Zhang J, Jin Y, Zhao X, Cai Z (2015) Adsorption of Pb(II), cd(II) and $\mathrm{Zn}$ (II) by extracellular polymeric substances extracted from aerobic granular sludge: efficiency of protein. J Enviro Chem Eng 3: $1223-1232$

Liu F, Csetenyi L, Gadd GM (2019) Amino acid secretion influences the size and composition of copper carbonate nanoparticles synthesized by ureolytic fungi. Appl Microbiol Biotechnol 103:7217-7230

Lupi C, Pasquali M, Dell'Era A (2005) Nickel and cobalt recycling from lithium-ion batteries by electrochemical processes. Waste Manag 25:215-220

Mishra J, Singh R, Arora NK (2017) Alleviation of heavy metal stress in plants and remediation of soil by rhizosphere microorganisms. Front Microbiol 8:e1706

Nancharaiah YV, Mohan SV, Lens PNL (2016) Biological and bioelectrochemical recovery of critical and scarce metals. Trends Biotechnol 34:137-155

Nanusha MY, Carlier JD, Carvalho GI, Costa MC, Paiva AP (2019) Separation and recovery of $\mathrm{Pd}$ and $\mathrm{Fe}$ as nanosized metal sulphides by combining solvent extraction with biological strategies based on the use of sulphate-reducing bacteria. Sep Purif Technol 212:747756

Peng W, Li X, Xiao S, Fan W (2018) Review of remediation technologies for sediments contaminated by heavy metals. J Soils Sediments 18: $1701-1719$

Perri E, Tucker ME, Słowakiewicz M, Whitaker F, Bowen L, Perrotta ID (2018) Carbonate and silicate biomineralization in a hypersaline microbial mat (Mesaieed sabkha, Qatar): roles of bacteria, extracellular polymeric substances and viruses. Sedimentology 65:12131245

Pinzari F, Zotti M, De Mico A, Calvini P (2010) Biodegradation of inorganic components in paper documents: formation of calcium oxalate crystals as a consequence of Aspergillus terreus Thom growth. Int Biodeterior Biodegrad 64:499-505

Rodrigues LEOC, Mansur MB (2010) Hydrometallurgical separation of rare earth elements, cobalt and nickel from spent nickel-metal-hydride batteries. J Power Sources 195:3735-3741

Song W, Pan X, Zhang D (2012) Lead complexation of soluble and bound extracellular polymeric substances from activated sludge: characterized with fluorescence spectroscopy and FTIR spectroscopy. Biotechnol Biotechnol Equip 26:3371-3377

Song W, Deng C, Pan X, Zhang D, Al-Misned FA, Mortuza MG, Gadd GM (2016) Effects of $\mathrm{pH}$ shock on hg(II) complexation by exopolymers from Acidithiobacillus ferrooxidans. Geomicrobiol J $33: 325-331$
Sun L, Qiu K (2012) Organic oxalate as leachant and precipitant for the recovery of valuable metals from spent lithium-ion batteries. Waste Manag 32:1575-1582

Sutjaritvorakul T, Gadd GM, Whalley AJS, Suntornvongsagul K, Sihanonth P (2016) Zinc oxalate crystal formation by Aspergillus nomius. Geomicrobiol J 33:289-293

Torres-Aravena EÁ, Duarte-Nass C, Azócar L, Mella-Herrera R, Rivas M, Jeison D (2018) Can microbially induced calcite precipitation (MICP) through a ureolytic pathway be successfully applied for removing heavy metals from wastewaters? Crystals $8:$ e438

Tourney J, Ngwenya BT (2014) The role of bacterial extracellular polymeric substances in geomicrobiology. Chem Geol 386:115-132

Tran KT, Van Luong T, An J-W, Kang D-J, Kim M-J, Tran T (2013) Recovery of magnesium from Uyuni Salar brine as high purity magnesium oxalate. Hydrometallurgy 138:93-99

Tsezos M (2009) Metal - microbes interactions: beyond environmental protection. Adv Mater Res 71-73:527-532

Wang J, Li Q, Li M-M, Chen T-H, Zhou Y-F, Yue Z-B (2014) Competitive adsorption of heavy metal by extracellular polymeric substances (EPS) extracted from sulfate reducing bacteria. Bioresour Technol 163:374-376

Wang Y, Qin J, Zhou S, Lin X, Ye L, Song C, Yan Y (2015) Identification of the function of extracellular polymeric substances (EPS) in denitrifying phosphorus removal sludge in the presence of copper ion. Water Res 73:252-264

Wang X, Song W, Qian H, Zhang D, Pan X, Gadd GM (2018) Stabilizing interaction of exopolymers with nano-se and impact on mercury immobilization in soil and groundwater. Environ Sci-Nano 5:456466

Wei Z, Hillier S, Gadd GM (2012) Biotransformation of manganese oxides by fungi: solubilization and production of manganese oxalate biominerals. Environ Microbiol 14:1744-1753

Wei L, Li Y, Noguera DR, Zhao N, Song Y, Ding J, Zhao Q, Cui F (2017) Adsorption of $\mathrm{Cu}^{2+}$ and $\mathrm{Zn}^{2+}$ by extracellular polymeric substances (EPS) in different sludges: effect of EPS fractional polarity on binding mechanism. J Hazard Mater 321:473-483

Yang Y, Ferrier J, Csetenyi L, Gadd GM (2019) Direct and indirect bioleaching of cobalt from low grade laterite and pyritic ores by Apergillus niger. Geomicrobiol J 36:940-949

Zhu T, Dittrich M (2016) Carbonate precipitation through microbial activities in natural environment, and their potential in biotechnology: a review. Front Bioeng Biotechnol 4:e4

Publisher's note Springer Nature remains neutral with regard to jurisdictional claims in published maps and institutional affiliations. 